\title{
O ENSINO E A PRÁTICA DA ENFERMAGEM CEARENSE: IMPLICAÇÕES \\ DA LEI 775 DE 1949
}

\section{THE TEACHING AND PRACTICE OF NURSING CEARENSE: IMPLICATIONS OF THE LAW 775 OF 1949}

\author{
Roberlandia Evangelista Lopes ${ }^{2}$ \\ Silvia Maria Nóbrega-Therrien ${ }^{3}$
}

\begin{abstract}
Resumo: O artigo objetivou analisar as implicações da Lei $\mathrm{n}^{\mathbf{0}} 775$, de 6 de agosto de 1949 no ensino e na prática da enfermagem cearense. Optou-se pela História Cultural como referencial teóricometodológico. Quatro professoras Enfermeiras da EESVP participaram do estudo. A coleta de informações foi de novembro de 2015 a janeiro de 2017. O artigo sustenta que a situação embrionária da formação e prática da enfermeira cearense, no período de 1949-1961, instala uma crise na profissão, na medida em que dois ocupacionais passam a ter o mesmo objeto de trabalho, no caso o cuidado. Assim, há o reconhecimento de uma só imagem e identificação de uma só profissão, especialmente pelo paciente. A projeção de uma única imagem implica diretamente na identidade da Enfermeira, assim como em seus espaços de prática e poder. Logo, constata-se a necessidade de conhecer a história da profissão para entender aonde se chegou ou aonde se chegará.
\end{abstract}

Palavras-chave: Enfermeiras e Enfermeiros; Educação Superior; Legislação; Auxiliar de Enfermagem.

\begin{abstract}
The article aimed to analyze the implications of Law No. 775, of August 6, 1949 in the Teaching and practice of Cearense Nursing. Cultural history was chosen as a theoretical-methodological framework. Four EESVP nurse teachers participated in the study. The period of information collection was from November 2015 to January 2017. The article maintains that the embryonic situation of the education and practice of the nurse in Ceará, in the period of 1949-1961, installs a crisis in the profession, in that two occupational conditions start to have the same object of work, in the case of care. Thus, there is the recognition of a single image and identification of a single profession, especially by the patient. The projection of a single image implies directly in the identity of the nurse, as well as in their spaces of practice and power. Thus, we see the need to know the history of the profession to understand where it has arrived or where it will arrive.
\end{abstract}

Keywords: Nurses and nurses; Higher education; Legislation; Nursing Assistant.

\section{Introdução}

Esta pesquisa teve por intuito analisar as implicações da Lei $\mathrm{n}^{\circ} 775$, de 6 de agosto de 1949 ou nova ordem no ensino e na prática da enfermagem cearense, considerando que ela impõe uma 'nova ordem' no momento em que institui legalmente

\footnotetext{
${ }^{1}$ Este texto é uma versão modificada de um artigo publicado no $7^{\circ}$ Congresso Ibero Americano em Investigação Qualitativa (LOPES; NÓBREGA-THERRIEN, 2018).

2 Doutora em Educação pela Universidade Estadual do Ceará (UECE). Professora da Faculdade INTA/UNINTA (UNINTA), Sobral, Ceará, Brasil. E-mail: roberlandialopes@ hotmail.com

${ }^{3}$ Pós Doutora pela Universidade de Valência (UV). Professora da Universidade Estadual do Ceará (UECE), Fortaleza, Ceará, Brasil. E-mail: $\underline{\text { silth@ hotmail.com }}$
} 
a criação de outra categoria ocupacional na Enfermagem, no caso, a de auxiliar de Enfermagem, que passa, oficialmente, a trabalhar na área da saúde junto com a Enfermeira 'diplomada', sobretudo no contexto hospitalar, bem como a dividir com ela (Enfermeira) o mesmo espaço de formação e campo de atuação.

Essa assertiva, de certo modo, conduz, a princípio, à discussão acerca dos aspectos vinculados à ordem existente antes da promulgação da mencionada Lei, uma vez que havia uma normatização oficial no Brasil para o exercício da enfermagem, ou melhor, uma forma de reconhecer e conceber a profissão. Nesse ínterim, destaca-se que, antes da vigência da 'nova ordem', o Decreto Oficial que regia a enfermagem no Brasil era o de $n^{\circ}$ 20.109, regimentado em 15 de junho de 1931. O conteúdo exposto no Decreto, ora referido, limitava-se ao direito do uso aos detentores do título de 'Enfermeira diplomada', no caso, profissão sujeita à fiscalização.

O Decreto de 15 de junho de 1931, ainda, determinava que a Escola Anna Neri fosse a Escola oficial padrão de ensino no país para formar esta profissional. Porém, mesmo diante dessa condição, é interessante pontuar que, para além da Escola Anna Neri, havia outras Escolas de Enfermagem no Brasil que, embora não atendessem a essa Escola padrão, seguiam regulamentação própria e ofereciam uma formação reconhecida oficialmente e com boas apreciações, entre elas vamos encontrar: a Escola de Enfermagem da Cruz Vermelha (criada em 1914 em São Paulo e em 1916 no Rio de Janeiro) e a Escola de Enfermagem Alfredo Pinto, nomeada assim em 1942, anteriormente, em 1890, denominavam-se de Escola Profissional de Enfermeiros e Enfermeiras.

Abrem-se um parêntese para registrar que, paralelo a esse contingente de Enfermagem mostrado, havia cursos de formação de Parteiras e de Obstetrizes (também referidas como Enfermeiras especializadas e obstétricas), figuras da enfermagem que não se poderia deixar de mencionar, mas que merecem um estudo à parte. Estas prestavam assistência profissional à mulher no período do ciclo gravídico-puerperal e eram formadas pelas Escolas de Medicina até o ano de 1949. Com tipificações e denominações variadas, a fiscalização e a regulamentação do exercício profissional desse contingente de pessoal, que exercia também as atividades de Enfermagem nos hospitais e em domicílio, eram de certa forma, fiscalizadas, no caso das Parteiras e das Enfermeiras Especializadas em Obstetrícia pelo médico, uma vez que eram as Escolas de Medicina as mentoras dessa formação. 
Feitas essas ponderações, sumariza-se que antes da Lei ${ }^{\circ} 775$, de 1949, tinha-se uma Escola padrão no Brasil e a intenção de formar a Enfermeira 'diplomada' vinculada a Escola Ana Neri e vários extratos leigos, bem como outros legalizados na profissão.

Diante deste cenário, questiona-se: afinal, o que motiva o fim da antiga ordem (1931-1949) para a instalação de uma nova ordem (1949-1961) no campo da educação da enfermagem no Brasil?

Em busca desta resposta se aponta que a questão da mão de obra na profissão começava a gerar um sério problema para a União, e os estados responderem as demandas crescentes que surgiam em busca de assistência de enfermagem, no caso, pois, nessa época (1940), havia cerca de 2.600 Enfermeiras, número irrisório em relação à população nacional, como revelam Santos et al., (2002).

As epidemias foram, também, motivo e fatores que contribuíram maciçamente para essa situação, uma vez que estavam entre as prioridades da agenda de saúde no Brasil em 1940, entre elas: a leishmaniose aparece no Rio de Janeiro (PESTANA; PESSOA, 1940). Outros fatores entende-se que foram, também, desencadeantes para a promulgação da Lei ou da 'nova ordem', entre eles assinala-se: a influência externa de outros países, à época, de conceber o trabalho e suas relações e segmentações, no caso, a divisão social do trabalho na Enfermagem (Inglaterra), além da aliança que se fortalecia entre o Estado e a Igreja no Brasil, notadamente favorecendo a presença maciça das congregações nos hospitais e nas Santas Casas com as religiosas que, com treinamento próprio, ministravam o cuidado amparado no seu lado espiritual.

Decorrentes dessas questões identificadas como motivadoras da implantação da 'nova ordem' ou da Lei n' 775 de 1949, seguem-se outras tantas relacionadas à qualidade do atendimento (diante de um exército de leigos realizando a assistência), à necessidade premente dos hospitais de pessoal habilitado e ao mercado de trabalho ávido por mão de obra de menor custo. Uma realidade complexa que parece fazer opção por uma resposta simplificada em nome da emergência quando promulgada a referida Lei, que neste artigo de denominou como o fez com muita pertinência Aline Silva da Fonte de $\mathrm{d}^{4}$ : 'nova ordem'.

Logo, decorrente das novas exigências da Lei na área (Enfermagem), passaram a vigorar a criação do curso que fará a formação da auxiliar de Enfermagem. A criação do

\footnotetext{
${ }^{4}$ Termo adotado a partir da leitura da tese intitulada: A Escola de Enfermagem Anna Neri e a nova ordem no campo da educação em enfermagem: (1949-1961), de autoria de Aline Silva da Fonte, defendida em 2009.
} 
curso oficializou, assim, esse profissional que era formado em menor tempo e, voltavase exclusivamente para o atendimento das necessidades hospitalares crescentes, conforme ditames da referida Lei.

O atributo da criação de uma nova categoria na enfermagem, com a formação mais encurtada em termos de anos, funções e exigências de ingresso diferenciadas, definindo na categoria dois níveis básicos para seu ensino - e, claro, na atuação -: o curso de Enfermagem, para a Enfermeira - que deveria durar 36 meses -, e o curso da auxiliar de Enfermagem - a ser realizado em 18 meses. Entre os critérios formativos para ingressar no curso para Enfermeiras havia a exigência do nível secundário, enquanto que no curso de auxiliar de enfermagem exigia-se o nível primário.

Nesses termos, identifica-se essa Lei como um 'divisor de águas' na profissão da Enfermeira - questão a qual se debruça esta pesquisa, tendo em vista refletir sobre e analisar a mencionada Lei, uma vez que a cisão formativa do cuidado em enfermagem entre duas categorias da profissão se legaliza. Essa legalização implica em uma diversidade de fatores que, ao longo deste artigo, vão sendo evidenciados. Um deles é que esse cuidado passava a ser praticamente 'cedido' aos poucos e, posteriormente, praticamente 'restritivo' ao auxiliar de Enfermagem, enquanto que à Enfermeira cabia, de forma crescente, preponderantemente atividades de supervisão dessa função. Esse fato é reforçado com o passar dos anos, em especial, em virtude das condições estruturais dos mercados brasileiro e cearense, no caso, e da escassez de pessoal qualificado para realizar o cuidado.

Assim, considera-se que a investigação proposta é de natureza inovadora e, uma vez que mesmo pesquisando temas provenientes de um passado recente, o faz a partir de base mais abrangente e oriunda de outras fontes de descobertas capazes de evidenciar outros fatos e entendimentos para o conhecimento das consequências que a Lei $\mathrm{n}^{\circ} 775$ de 1949 trouxe para profissão Enfermeira, devido, principalmente, à forte e oficial cisão na formação e, consequentemente, prestação do cuidado - a função maior e a essência da profissão - que passa a ser executado, sobretudo, pela auxiliar de enfermagem.

Dito isto, defende-se neste estudo que com a formação oficializada da auxiliar de Enfermagem através da Lei $\mathrm{n}^{\circ} 775$, de 6 de agosto de 1949, para desenvolver juntamente com a Enfermeira em processo de profissionalização ações de assistência junto ao paciente hospitalizado, promoveu-se uma 'nova ordem' no campo desta profissão, que gerou consequências em sua formação e na função por ela exercida em 
seu reconhecimento social, identitário e de campo de poder. Esta ideação, também, foi defendida por Lopes e Nóbrega Therrien (2018).

Nesse sentido, questiona-se: quais as implicações da Lei 775 de 1949 para o ensino e a prática da Enfermagem Cearense?

\section{Metodologia}

Tendo-se consciência de que existem inúmeras formas de compreender o passado, optou-se pela História Cultural $(\mathrm{HC})$ como referencial teórico-metodológico para desenvolver esta investigação. Esta pesquisa, então, constitui-se em um estudo de caráter essencialmente histórico, tendo como campo empírico a Escola de Enfermagem São Vicente de Paulo (EESVP).

Diante das escolhas e orientações referidas acima acerca da HC, fez-se a decisão de especificá-la, ou melhor, focar a lente da pesquisa no relacionamento da $\mathrm{HC}$ com as fontes e seu tratamento. Feita estas considerações e nessa direção, prioriza-se, metodologicamente, a pesquisa documental histórica nesta pesquisa para se analisar os processos envolvidos em volta da nova ordem e, assim, utilizou-se dos seguintes documentos: a Lei ${ }^{\circ} 775$, de 6 de agosto de 1949, e seu respectivo Decreto $n^{\circ} 27.426$, de 14 de novembro de 1949, para a formação da Enfermeira. O Quadro 1 destaca estes documentos, destacand o título do documento, o ano de promulgação do documento, o órgão responsável por sua vinculação e a análise documental com base em Luchese (2014).

Quadro1: Documentos que serviu a este estudo. Fortaleza, Brasil, 2018

\begin{tabular}{|c|c|c|}
\hline $\begin{array}{l}\text { Título do } \\
\text { documento }\end{array}$ & $\begin{array}{c}\text { Órgão } \\
\text { responsável por } \\
\text { sua veiculação }\end{array}$ & Análise documental conforme Luchese (2014) \\
\hline $\begin{array}{l}\text { Decreto }^{\circ} \\
20.109\end{array}$ & $\begin{array}{l}\text { Diário Oficial da } \\
\text { União }\end{array}$ & $\begin{array}{l}\text { Procedimento interno: a ideia central do ato normativo é informar a } \\
\text { regulamentação do exercício da enfermagem no Brasil e fixa as } \\
\text { condições para a equiparação das escolas de enfermagem. Objetivo } \\
\text { secundário da Lei: referir as instruçães relativas ao processo de } \\
\text { exame serão organizadas pela diretoria da Escola Anna Neri. } \\
\text { Materialidade do documento: em destaque a ênfase que o título de } \\
\text { enfermeiro diplomado ou enfermeira diplomada será oficializado } \\
\text { pela Escola Ana Neri. O Gênero textual adotado no documento é do } \\
\text { âmbito jurídico. Implicitamente se percebe que, no Brasil daquela } \\
\text { época, o tipo de formação almejado (social e politicamente) era o } \\
\text { instituído pela Escola Ana Neri no Rio de Janeiro. }\end{array}$ \\
\hline $\begin{array}{c}\text { Lei }{ }^{\circ} 775 \text { (6 } \\
\text { de agosto de } \\
\text { 1949) }\end{array}$ & $\begin{array}{l}\text { Diário Oficial da } \\
\text { União }\end{array}$ & $\begin{array}{l}\text { Procedimento interno: a Lei dispõe sobre o ensino de enfermagem no } \\
\text { país. Secundariamente, refere o funcionamento de dois cursos na } \\
\text { enfermagem, o período de funcionamento de cada curso, as } \\
\text { exigências na matrícula de cada curso, o exame de admissão, a } \\
\text { autorização para o funcionamento de cada curso e a adequação das } \\
\text { escolas já existentes. O gênero da escrita é jurídico. }\end{array}$ \\
\hline
\end{tabular}




\begin{tabular}{|l|l|l|}
\hline & $\begin{array}{l}\text { Materialidade do documento: há ênfase na distinção do curso de } \\
\text { Enfermagem e Auxiliar de Enfermagem. Implicitamente se percebe } \\
\text { uma divisão da formação, entre dimensão intelectual e manual. }\end{array}$ \\
\hline
\end{tabular}

Fonte: Elaborado pela autora

Fez-se, também, o uso de depoimentos e/ou entrevistas orais como fontes documentais, importantes para complementar dados e ou aprofundar as discussões levantadas nesta pesquisa. Essa fonte do relato oral foi colhida através de entrevistas temáticas. Esse tipo de procedimento metodológico versa sobre a inserção do indivíduo no tema escolhido, porquanto "Escolhem-se pessoas que dele participaram ou que tiveram conhecimento para entrevistá-las a respeito" (ALBERTI, 2005, p. 38). Considera-se importante pontuar que as pesquisas inseridas no campo da enfermagem não costumam referir o nome original dos entrevistados, com vista à resolução $\mathrm{n}^{\circ} 466$ de 12, de dezembro de 2012, que resguarda os aspectos éticos da pesquisa ao lidar com seres humanos. Diante disto, se toma a decisão de substituir nome das professoras entrevistadas. Assim, utiliza-se, a letra E de Enfermeira (formação básica das entrevistadas), juntamente com o numeral cardinal na ordem em que ocorreu o primeiro contato com as entrevistadas. Exemplificando: E1 (Enfermeira e primeiro contato com a pesquisadora), E2 (Enfermeira e segundo contato com a pesquisadora) e assim sucessivamente.

Assim, foi tomada a palavra gravada de quatro professoras Enfermeiras da EESVP e que tiveram inserção direta junto não somente ao curso de formação da Enfermeira, mas, sobretudo, no curso e/ou programa de ensino da Auxiliar de enfermagem, em Fortaleza/Ceará.

No Quadro 2 é possível identificar os codinomes adotados e referidos a pouco das entrevistadas, a data de nascimento, sua vinculação à instituição e o período. Destaca-se, entretanto, que os nomes eleitos para manter o anonimato das professoras representam figuras importantes na trajetória histórica da enfermagem Cearense.

Quadro 2: Entrevistadas da pesquisa. Fortaleza, Brasil, 2018

\begin{tabular}{|c|l|l|}
\hline Entrevistada & \multicolumn{1}{|c|}{ Vinculação à instituição } & \multicolumn{1}{|c|}{$\begin{array}{c}\text { Período de } \\
\text { atuação }\end{array}$} \\
\hline \multirow{3}{*}{ E1 } & $\begin{array}{l}\text { 1) Graduação em Enfermagem EESVP } \\
\text { 2) Secretária do curso de Enfermagem } \\
\text { 3) Coordenadora do Curso de Auxiliar de } \\
\text { Enfermagem }\end{array}$ & $\begin{array}{l}1955 \\
1965-1976 \\
1977\end{array}$ \\
\hline \multirow{2}{*}{ E2 } & 1) Graduação em Enfermagem EESVP & 1959 \\
& 2) Professora do curso de Enfermagem & 1981 \\
& 3) Professora do curso de Auxiliar de enfermagem & 1982 \\
\hline
\end{tabular}




\begin{tabular}{|c|l|l|}
\hline \multirow{5}{*}{ E3 } & $\begin{array}{l}\text { 1) Graduação em Enfermagem - EESVP - Unidade } \\
\text { agregada à Universidade Federal do Ceará }\end{array}$ & 1971 \\
2) Professora e coordenadora do curso de & $1983-1989$ \\
& $\begin{array}{l}\text { Enfermagem } \\
\text { 3) Professora e coordenadora do curso de Auxiliar de } \\
\text { enfermagem }\end{array}$ & \\
\hline \multirow{2}{*}{ E4 } & $\begin{array}{l}\text { 1) Graduação em Enfermagem- EESVP - Unidade } \\
\text { agregada à Universidade Federal do Ceará } \\
\text { 2) Professora do curso de Enfermagem } \\
\text { 3) Professora e coordenadora do curso de Auxiliar de } \\
\text { enfermagem }\end{array}$ & 1973 \\
\hline
\end{tabular}

Fonte: Elaborado pela autora

Destaca-se que em alguns momentos da entrevista foram mostrados para consultas das professoras o Decreto $\mathrm{n}^{\mathrm{o}} 27.496$, de 14 de novembro de 1949, que regulamentou a Lei $n^{\circ} 775$, de 6 de agosto de 1949, assim como o Decreto ${ }^{\circ} 4.244$ de 1942 com a finalidade de contextualizar e situar as questões no tempo da história dos cursos, bem como ativar a memória das professoras.

Após a recolha do documento sonoro que foi gravado e autorizado pelas professoras, se realizou a transcrição bruta das entrevistas temáticas. Depois a etapa da transcrição foi feita a conferência de fidelidade do texto (ALBERTI, 2005). Foi escutada a gravação das professoras novamente, verificando se a transcrição estava de acordo com as falas, deixando o texto mais acessível para interpretação.

A última etapa para o tratamento da entrevista é o copidesque, que segundo Alberti (2005) é o ajustamento do texto para a atividade de leitura, com atenção à pontuação, que desempenha papel fundamental para a interpretação das falas; é mais precisamente a correção das regras da Língua Portuguesa, assim como a criação e categorias. Por fim, passou-se o diálogo das fontes com a teoria. Para transformar as informações obtidas durante todo o desenvolvimento da pesquisa em documentos, nos debruçamos sobre os mesmos, por servirem de fonte para a descrição, análise e interpretação do problema à luz do referencial teórico, fazendo surgir novos conceitos.

O período da coleta de informações foi de novembro de 2015 a janeiro de 2017. Salienta-se, ainda, que uma versão preliminar deste artigo foi apresentada no sétimo Congresso Ibero Americano em Investigação Qualitativa, em 2018 (LOPES; NÓBREGA-THERRIEN, 2018). 


\section{Resultados e Discussões}

A princípio, faz uma contextualização de profissionalização a fim de imbricar esta discussão com os resultados do estudo. Assim, com relação à situação de profissionalização embrionária da enfermagem no país, consequentemente, no Ceará, pós-nova ordem, apresenta-se, a compreensão nessa pesquisa do conceito de profissão e seus caminhos para profissionalização.

O debate sobre questões que geram em torno da história natural da profissionalização até os anos de 1960 é debatido nos escritos de sociólogos norteamericanos como Parsons (1987) e Ehrenreich e English (1981). Somente na década de 1970 os estudos sobre profissão passam a ter como foco principal os fatores econômicos e políticos que a ela se encontram relacionados (NÓBREGA-THERRIEN; ALMEIDA, 2007).

A teoria das profissões de Parsons (1967) é a que oferece maior sustentação a maioria de classificações que surgem à época anos 1960, para distinguir uma profissão de uma ocupação por exemplo. Para ele os atributos necessários podem ser resumidos a “dedicação exclusiva e aquisição prévia de competência técnica, que se fundamenta em um corpo de conhecimentos científicos e em um código deontológico próprio" (PARSONS, 1967, p. 34-49). Somente no início da década de 1980, Alarcon, em seu trabalho sobre a Enfermagem, citado nos escritos de Nóbrega-Therrien e Almeida (2007, p. 54), traz oito requisitos que no entendimento dela diferenciam a natureza de uma profissão, que são:cumpre uma função social, tem um corpo de conhecimentos científicos e técnicos, requer uma formação ou capacitação formal para seus profissionais, possui um código de ética, define sua própria organização ou estrutura quando envolve, no desenvolvimento de sua função, pessoas de diferentes categorias, possui uma legislação própria, possui uma estrutura nacional responsável pela formação de seus membros; edesenvolve sua própria forma de educação cientifica e gremial em nível nacional e internacional.

Espelhada nestes autores, em outras palavras a Enfermagem, no período de 1949-1961 buscava sua profissionalização focada no exercício da prática, ancorada, sobretudo na competência técnica, que procurava se ancorar nos idos de 1970 e 1980 com mais força, nos princípios científicos. Então, pode-se dizer que a implantação da 'nova ordem' cria de certa forma uma crise para as Enfermeiras diplomadas e as escolas padrão e consequentemente para própria profissão no Brasil. Crise que ocorre entre 
outros fatores, pela indefinição de funções entre as várias categorias já existentes na profissão, agravada pela legalização da figura da auxiliar de enfermagem. As Enfermeiras no âmbito do seu exercício, ainda não tinham códigos, regras que regulamentassem seu exercício profissional até mesmo para equipara-se com outras profissões consolidas no país, como: médicos, cirurgiões, farmacêuticos/boticários, dentistas e parteiras que, em 1850, iniciaram suas regulamentações.

Consta-se posteriormente que a crise é duradoura e com ela surgem outras pequenas crises internas e, portanto, relacionadas, no caso, aos membros que com o tempo vão constituir a equipe de enfermagem. A Auxiliar é legalmente introduzida na enfermagem em 1949 e em 1966 é a vez do técnico de enfermagem. Deste movimento em busca de profissionalização com o foco na questão interna da formação e função diferenciada dos membros da equipe.

Silva (1986, p. 87) nos fornece uma importante análise dessa crise que chega ainda a meados da década de 1980:

\begin{abstract}
são também ambíguas as referências genéricas e unívocas a crise da enfermagem, pois na medida em que esta área se caracteriza por composição heterogênea e de se supor que a propalada crise assuma aspectos diversos para as várias categorias, ou melhor, que a crise não seja unívoca, mas multifacetária. Frequentemente, as alusões à crise da enfermagem dizem respeito de fato, a crise percebida e vivida pela categoria das Enfermeiras. Sem dúvida, uma crise das Enfermeiras não está isolada de uma crise na enfermagem, que por sua vez, não está isolada da sociedade inclusiva, mas é preciso distinguir as respectivas especificidades para apreender-se a dialética da parte e do todo, do singular e do universal.
\end{abstract}

Como no Ceará o reconhecimento da profissão por ser ainda mais prematuro em relação ao eixo Rio e São Paulo, uma vez que a EESVP contava somente com três turmas de enfermeiras diplomadas, entende-se que as consequências e implicações, vão ser mais fortes. Constata-se que no ensino como já explicitado nos programas da Enfermeira e da Auxiliar, em seguida com mais força nas unidades de estagio prático e posteriormente no campo profissional, [consequências e implicações] não mais de caráter estudantil, mas no foco de atuação dos seus profissionais, ocupacionais, especialmente no campo hospitalar.

A Figura 1 a seguir desenha esse cenário da chegada da 'nova ordem' e, as consequências e implicações para a Enfermeira Cearense. 
Figura 1: Cenário da chegada da nova ordem no Ceará e as consequências para Enfermeira. Fortaleza, Brasil, 2019

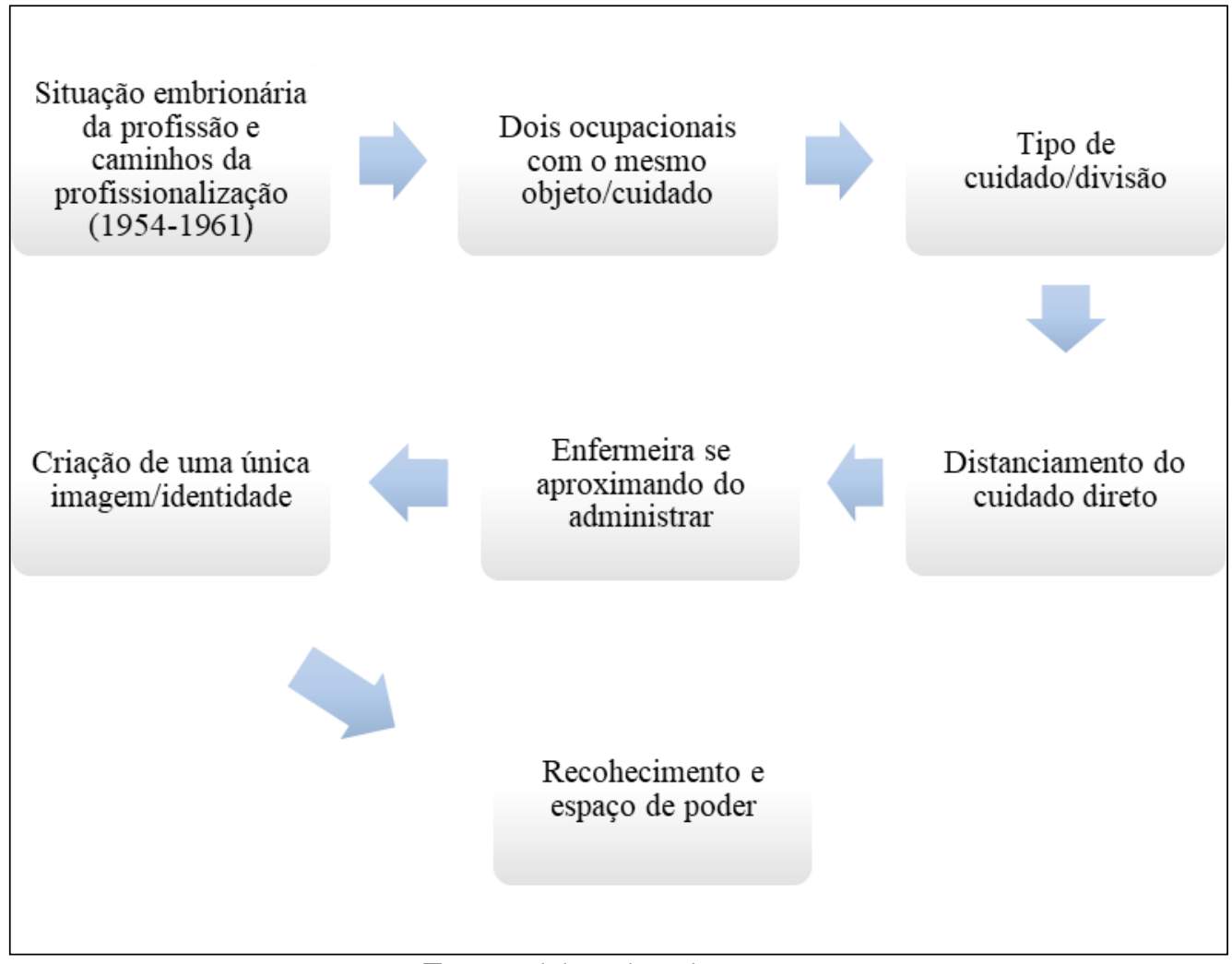

Fonte: Elaborado pelas autoras

Com base na Figura 1, em uma análise ampla retoma-se a dificuldade de profissionalização da Enfermeira nesse período e, a partir daí infere-se o surgimento de consequências e implicações, fruto, sobretudo, da criação e promulgação da 'nova ordem'. Entende-se a complexidade destes fatores expostos de forma simples e estática nesse cenário, uma vez que são acontecimentos que estão em movimento e que a força entre eles geraram implicações e, portanto, consequências - tanto na formação como na prática da profissão, com as mais variadas inferências nestes dois campos específicos e em sua relação com as estruturas maiores que envolvem outras profissões, sobretudo a do médico e o campo, especialmente hospitalar e finalmente o setor saúde como um todo.

Porém, em uma análise mais focada da Figura 1, as consequências dos acontecimentos que fazem passar de um quadro a outro demonstram especificamente que esse novo trabalhador no campo da enfermagem cearense vai movimentar o 'jogo' no cenário. 'Por ser cada vez mais crescente em número dentro das unidades hospitalares vai aproxima-se mais do paciente do que da Enfermeira, especialmente, referente ao cuidado direto que é dispensado a ele, apropriação facilitada, também, por falta de clareza de atribuições distinguidas. Lembrando que o cenário à época tinha um 
contingente limitado de Enfermeiras e, presença mais prevalente de Auxiliares de enfermagem. Isto, de certo modo, conduz a tomar para si as atribuições especificas da Enfermeira, alicerçadas na formação e nos fundamentos para sua realização, assim como acontecia à apropriação pela falta de profissionais. Com relação a esta questão, uma das enfermeiras entrevistadas a professora E1, que por muito tempo foi coordenadora do curso de auxiliar de enfermagem da EESVP, sobre um só campo de prática e que posteriormente se transformava em campo de trabalho profissional para Enfermeira e a Auxiliar, refere:

como elas dividiam o mesmo espaço no hospital, a Enfermeira começava a demarcar alguns espaços de atuação. Em geral, a aluna Enfermeira fazia as funções que considerava mais administrativa, como, observação e relatórios. Era difícil uma Enfermeira formada pegar no pesado. As primeiras Enfermeiras diplomadas no Ceará não queriam fazer certas coisas. Achavamse muito importantes porque eram as Enfermeiras Ana Neri. Então a Auxiliar fazia tudo, principalmente o mais pesado na unidade e com o paciente.

Outras professoras entrevistadas trazem em suas falas a dimensão dos conflitos internos não só na divisão de tarefas no campo hospital, mas em outros espaços de convivência quando assinalam:

as primeiras Enfermeiras formadas pela escola não queriam realizar certas coisas. Com extração de urina, asseio do paciente, banho no leito, por exemplo. Se achavam superiores as Auxiliares por que eram Enfermeiras Ana Neri (E1).

as Auxiliares da Escola receberam um ônibus escolar da UNICEF para se dirigirem ao campo de estágio. Aí, quando as estudantes de Enfermagem entravam no ônibus elas sentavam na frente e ocupavam os melhores lugares ficando as alunas do auxiliar, sempre com os assentos na parte de traz (E2).

A fala primeira da professora e coordenadora do curso de Auxiliares da EESVP remete a constatação de uma posição, observada no campo de prática que vai distanciando consciente ou inconscientemente a Enfermeira cearense de alguns cuidados junto ao paciente e de forma gradativa entende-se que de muitos outros [cuidados], de certa forma alicerçada também no aumento cada vez maior do contingente de Auxiliares de enfermagem que se inseriam no mercado de trabalho, sobretudo o hospitalar, em detrimento do número crescente de enfermeiras formadas, mas em escala muito inferior ao deste contingente.

Entende-se, também, que o afastamento da Enfermeira dos cuidados junto ao paciente configura uma forma de busca de diferenciação entre suas funções e as da auxiliar. O contexto, também, contribuía para que ela assumisse essa posição que a colocava cada vez mais distante do cuidado inclusive, segundo Melo (1986), na década de 1980 ela já assinalava que esse foi um lugar (assistência direta) que nunca de fato foi 
ocupado por esta profissional. O que de certa forma fortalece o que se coloca como consequência da implantação da 'nova ordem'.

Essa busca da Enfermeira pela diferenciação em pequenos espaços e, sobretudo, na assistência prestada em campo hospitalar, termina por aproximá-la cada vez mais das atividades de supervisão e administração (mais detalhada a seguir), o que vai se fortalecer na profissão com o passar do tempo.

Assim, o objeto da enfermagem [assistência, o cuidado] se fragmenta entre manual e intelectual, sendo que esse último se constitui na principal tarefa da Enfermeira. Nesse sentido, as ideias de Carvalho e Castro (1979, p. 52) contribuem nesta discussão quando assinalam no final da década de 1970, que esta situação [de distanciamento do cuidado direto] só se agrava.

\footnotetext{
As funções desempenhadas pela enfermeira caracterizam, destarte, uma supervalorização dos aspectos administrativos e de supervisão do pessoal auxiliar, em detrimento dos aspectos técnicos assistenciais, apesar de serem estes que evidenciam perícia e evidência.
}

Por outro lado em tempos mais recentes autores como, Freitas, Oguisso e Ruiz (2016) justificam a decisão da Enfermeira pelo administrar que remota na profissão há mais de um século, em especial, referem que a gênese e incorporação do saber administrativo em enfermagem, surgiu em registro a partir das obras El arte de Enfermaría, de autoria do enfermeiro espanhol José Bueno y González (escrita em 1833), e pouco tempo depois se encontra, também, nos escritos Notas sobre a enfermagem, publicação de Florence Nightingale (escrita em 1859), uma vez que essas produções possibilitam alicerçar as dimensões do saber administrativo em enfermagem (ou suas raízes).

Outro fator importante e inerente a esta questão estaria na busca da Enfermeira por espaço, reconhecimento e poder. Questões que não se pretende discutir nesta pesquisa e que teria toda base de fundamentação nos escritos de Pierre Bourdieu (2011), mas que se inserem como fortes elementos neste contexto. Dizendo em outras palavras, as atividades de administrar, constituem hoje (2019) atividades legalizadas e reconhecidas socialmente com atividades de excelência da Enfermeira, especialmente pela Lei $n^{\circ} 7.498$ de 1986 e seu Decreto $n^{\circ} 94.406$ de 1987, que as colocam (atividades de administração) como privativa desta categoria.

É importante dizer que esta pesquisa não nega a importância deste fazer e as glórias que trouxe a profissão, assim como se concorda com a necessidade de fundamentos e preparação da Enfermeira para a administração, mas que este não seja 
um campo que vai ser com o decorrer do tempo apropriado em demasia pela Enfermeira, trazendo, essa apropriação algumas consequências para profissão.

Assim, essa busca pela apropriação de outras funções que não a assistencial do cuidado junto ao paciente, parece não ser assumida inicialmente pela Enfermeira somente como forma de distinção da auxiliar de enfermagem, mas também, posteriormente, por questões acima explicitadas por Nóbrega-Therrien e Almeida (2007). Contudo, acredita-se que a inserção de novo membro, agora formado, instiga a Enfermeira a validar legalmente e a garantir esse espaço tão durante conquistado pelas Enfermeiras nas décadas de 1920 a 1940.

Silva (1986), referindo-se às primeiras Enfermeiras diplomadas no Brasil na década de 1920, afirma que as Escolas procuravam desenvolver qualidades intelectuais da nova Enfermeira, entre ela supervisão e o ensino, deixando de lado o cuidado direto com o paciente como forma de firmar respeitabilidade e a cientificidade da profissão. A valorização da profissão, segundo se acreditava, se daria na medida em que elas se separassem dos grupos que exerciam cuidado ao doente.

Mas, como consequência, 24 anos após a nova ordem, foi possível colher em Santos (1973) que a Enfermeira, cônscia de seu status e elevado nível de instrução não dá mais cuidados aos enfermos. O que teria ocorrido com a institucionalização desses papéis, questiona a autora. A resposta dessa pergunta requer a fala de Silva (1986), especificamente sobre a situação-problema cuidado direto e indireto:

\begin{abstract}
sem dúvida, a assistência de enfermagem é a razão de ser da enfermagem em seu conjunto, mas a sua realização necessita de uma série de atividades que não são específicas de enfermagem, embora para ela esteja voltada. [...] Este fato é responsável, penso, [...] para problemática do status-papel da Enfermeira, em cujas raízes se encontra o dilema cuidado direto x cuidado indireto (SILVA, 1986, p. 120).
\end{abstract}

Dito isto, ainda se coloca que as circunstâncias de oficialização do curso de auxiliar de enfermagem no Brasil, exigiram das Enfermeiras outras alternativas que pudesse garantir a distinções entre esses dois membros, especialmente no Ceará, uma vez que a EESVP tratou de empregar símbolos ou representações objetais ${ }^{5}$ para sanar essa confusão, entre eles o uso de uniforme pelas alunas Auxiliares diferenciados da Enfermeira. Essas representações objetais eram delimitadas por esta escola, também, como forma de garantir suas posições no campo na profissão.

\footnotetext{
${ }^{5}$ Elaine Franco Ribeiro e Fernando Porto (2011), mediante as noções de Bourdieu (autor representante da $\mathrm{HC}$ ), indicam que são signos exteriores ao corpo, como por exemplo, bandeiras, uniformes, insígnias e emblemas, associados aos signos incorporados, ou seja, poses e posturas.
} 
A propósito dessa iniciativa, a professora E1 relembra que: "o paciente diferenciava a Enfermeira da auxiliar de Enfermagem pelo uniforme". Assim, nos anos iniciais desta escola o uniforme instituído para auxiliar de enfermagem era diferente do que era usado pela Enfermeira. A primeira vestimenta a ser usados pelas Auxiliares era de um tecido na cor creme, posteriormente passou a ser na cor azul claro. Elas ainda usavam um gorro e sapatos brancos fechados. A adesão a esse tipo de uniforme trata da elaboração de um grupo de ideais-imagens construídos pelas Enfermeiras do Ceará, a fim de estabelecer distinções entre a Enfermeira e a auxiliar de enfermagem no Estado, até porque elaborar novos trajes para diferenciar-se na aparência e na hierarquia sempre foi o pensamento dominante nas corporações militares e sociedades de classe.

Depreende-se disto que a utilização dos uniformes é uma das estratégias de distinção, que pode ser denominada de distinção hierarquizada. Isto, do ponto de vista das Enfermeiras da EESVP poderia facilitar a correlação da imagem da auxiliar de enfermagem como figura distinta da Enfermeira, uma vez que entende-se que a época, por questões já explicitadas, não era fácil, daí o reconhecimento de uma só imagem e identificação de uma só profissão ou profissional.

Sobre imagem profissional, esta pesquisa a entende como:

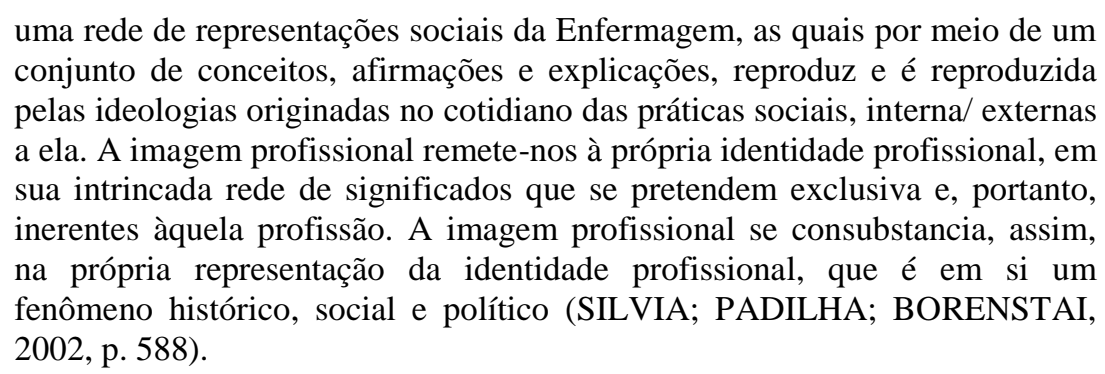

Dito de outra maneira, a imagem são as representações criadas pelas pessoas, e pelos próprios membros da categoria, relacionada à suas características e significados exclusivos. Dessa forma, importa pontuar que havia duas imagens concorrentes no período da nova ordem no Ceará, ou seja, Enfermeira e auxiliar de enfermagem, e estas, mantinham certo nexus no sentido da prática do cuidar, o que leva a considerar certa aproximação, vinculadas ao público, por ações que se mesclavam. Isso imprimia necessariamente situações confusas entre as duas profissões até porque que não havia legislação do exercício profissional até 1961.

Essa projeção de imagem vai perpassar ao longo do caminho histórico da profissão configurando uma única imagem aos olhos do paciente e consequentemente da sociedade em geral. Santos (1973), 24 anos após a implantação da 'nova ordem', e já 
sob a presença da legalização do exercício profissional por meio do Decreto $\mathrm{n}^{\circ}$ 50.387/61 de 1961, ainda afirmava que para o paciente, principalmente, o de escolaridade mais elementar há poucas oportunidades para diferenciar quem é Enfermeira e Auxiliares de Enfermagem.

Esse entendimento também é compartilhado por Nobrega-Therrien e Ameida (2007, p. 73), 58 anos após a nova ordem, quando assinala, "que mesmo que a categoria tenha encontrado amparo legal, nesse caso, já com a implantação do Decreto 94.406 de 1987 (do exercício profissional) estabelecendo distinção entre os agentes da profissão, a ambiguidade da denominação profissional, ainda se mantêm, ou seja, toda mulher que veste uniforme branco e caminha nos corredores dos hospitais é identificada como Enfermeira".

Assim, como a imagem remete à identidade profissional, as reformulações nas regras de ensino da enfermagem, ou aceite da nova ordem no Ceará, significou uma caminhada em direção a uma nova reconfiguração profissional da Enfermeira da EESVP.

No campo da formação os programas de ensino buscaram cumprir esse papel de diferenciação dos cursos [enfermeira e auxiliar] no tempo, nas exigências de entrada e visivelmente observado nos conteúdos teóricos mais extensos e fundamentados. Mas, como a época era do ensino da técnica pela competência técnica, só posteriormente da técnica validada em princípios científicos, a época que vai até 1961, não contribui de forma significativa para o reconhecimento da enfermeira como figura distinta em meio a outras categorias. O campo prático dificultava enormemente essa distinção, por razões já explicitadas. Questão que está posta na raiz da identidade da Enfermeira, especialmente pela ameaça da descaracterização profissional ou a perda de sua especificidade profissional.

Nesse sentido tem-se velado seu reconhecimento. Então, entende-se que inconscientemente como forma de garantir um projeto identitário de profissão e poder a Enfermagem cearense a época de 1954-1961, buscou alternativas de reconhecimento social cristalizando uma organização heterogênea e fragmentada da profissão, distanciando-se da sua função pela qual é reconhecida enquanto tal - a assistência, o cuidado. Entende-se que a 'nova ordem' trouxe essa consequência para a profissão (uma das) que teve implicações que ainda repercutem nos tempos atuais deste profissional. 


\section{Considerações finais}

O artigo sustenta que a situação embrionária da formação e prática da enfermeira cearense, no período de 1949-1961, instala uma crise na profissão, na medida em que dois ocupacionais passam a ter o mesmo objeto de trabalho, no caso o cuidado. A Enfermeira cearense no campo, sobretudo, hospitalar busca estratégias para se distanciar da auxiliar de Enfermagem, se distanciando do cuidado direto em detrimento da aproximação crescente das atividades de administração e supervisão. Utilizando-se também de representações objetais, no caso, a instituição de uniformes pela EESVP em uma tentativa de diferenciar a auxiliar de enfermagem; uma posição que se mostrou sinuosa e não conseguiu definir os campos e as diferenças, a época.

Essa condição, ora referida, instala no interior da profissão o reconhecimento de uma só imagem e identificação de uma só profissão ou profissional, especialmente pelo paciente. A projeção de uma única imagem implica diretamente na identidade da Enfermeira, assim como em seus espaços de prática e poder.

Logo, diante dos resultados obtidos, também se chega a um ponto de nova partida quando se sugere que estudos futuros voltem à temática, especialmente no que se refere à visão precipitada que a existência da auxiliar de enfermagem se deu em decorrência exclusiva da exigência do mundo do trabalho, porém, essa não é a real justificativa. Com o aceite da Lei n ${ }^{\circ} 775$ de 1949 pela profissão, também, transformouse o objeto de atuação da Enfermeira no Brasil e, consequentemente, no Ceará. Atendeu-se a lógica de mercado e, essas decisões trouxeram a Enfermeira até aqui: imersa em um contexto em que ela, muitas vezes, assim como outros, não se reconhece em sua plenitude, em que a população, muitas vezes, não reconhece o seu fazer, assim como, o entendimento do que ser Enfermeira, é ceder àquilo que nos faz ser Enfermeira, ou seja, o cuidado direto. Interessa, também, dizer que estudos futuros possam ampliar o campo de investigação para quando acontece a inclusão de mais um membro que contribui para formar o que se conhece desde então (1966) como equipe de enfermagem. E, é valido informar que o texto apresenta limitações, entre elas, a quantidade de entrevistadas, ou seja, apenas quatro professoras. Porém, sinaliza-se que apesar deste quantitativo o estudo traz uma relevância histórica a categoria, especialmente pelo tempo de vivências das entrevistadas nos cursos de formação da Enfermeira e da Auxiliar de Enfermagem cearense. 
Lacunas em estudos sobre a profissão e as condições ímpares de profissionalização da Enfermeira que enfrentou uma grande crise com a criação e implantação da nova ordem, são importantíssimos para se compreender como o passado conduziu o nosso presente, na tentativa de, se for o caso, redirecionar-se o futuro da Enfermeira. Logo, constata-se a necessidade de conhecer a história da profissão para entender aonde se chegou ou aonde se chegará; a (re) leitura de épocas e situações cunhadas em volta de cada passo dado, cada elemento agregado e retirado da profissão.

Agradecimento. As autoras agradecem o financiamento da Fundação Cearense de Apoio ao Desenvolvimento Científico e Tecnológico-FUNCAP pelo fomento durante o exercício do doutorado no programa de pós-graduação em educação pela Universidade Estadual do Ceará-UECE, Fortaleza-CE, Brasil.

\section{Referências}

ALBERTI, V. Manual de História Oral. 3. ed. Rio de Janeiro: FGV, 2005.

BOURDIEU, P. Economia das trocas simbólicas. 5. ed. São Paulo: Perspectiva. 2011.

BRASIL. Casa Civil. Subchefia para assuntos Jurídicos. Decreto $\mathbf{n}^{\circ} \mathbf{2 0 . 1 0 9}$, de 15 de junho de 1931. Regula o exercício da enfermagem no Brasil e fixa, as condições para a equiparação das escolas de enfermagem. Rio de Janeiro, 1931.

BRASIL. Casa Civil. Subchefia para assuntos Jurídicos. Decreto ${ }^{\mathbf{0}}$ 4.244, de 9 de abril de 1942. Aprova o projeto de lei orgânica do ensino secundário. Rio de Janeito, 1942.

BRASIL. Casa Civil. Subchefia para assuntos Jurídicos. Lei no 775, de 6 de agosto de 1949. Dispõe sobre ensino de enfermagem no País e dá outras providências. Rio de Janeito, 1949.

BRASIL. Casa Civil. Subchefia para assuntos Jurídicos. Decreto no 27.497 , de 14 de novembro de 1949. Aprova o regulamento básico para os cursos de enfermagem e Auxiliares de enfermagem. Rio de Janeito, 1949.

BRASIL. Casa Civil. Subchefia para assuntos Jurídicos. Lei n⿳0 7498, de 25 de junho de 1986 Dispõe sobre a regulamentação do exercício da Enfermagem e dá outras providências. Brasilia, 1986.

BRASIL. Casa Civil. Subchefia para assuntos Jurídicos. Lei $\mathbf{n}^{\mathbf{0}} \mathbf{7 4 9 8}$, de 8 de junho de 1987. Regulamenta a Lei $\mathrm{n}^{\circ} 7.498$, de 25 de junho de 1986, que dispõe sobre o exercício da Enfermagem, e dá outras providências. Brasilia, 1987.

BRASIL. Conselho Nacional de Saúde do Ministério da Saúde. Resolução 466, de 12 de dezembro de 2012. Brasília, 2012

CARVALHO, V.; CASTRO, I. B. Reflexões sobre a prática da enfermagem. In: CONGRESSO BRASILEIRO DE ENFERMAGEM, 31., 1979, Fortaleza. Anais... Brasília: ABEn 1979. p. 519. 
EHENREICH, B.; ENGLISH, D. Brujas, comadronas y enfermeiras. Historia de las sanadoras. 3.ed. Barcelona: Lasal, 1981.

FONSECA, E. F.; PORTO, F. Enfermeiras Parteiras e Uniforme: indícios e representações objetais na construção da identidade profissional. Rev. enferm. UERJ, Rio de Janeiro, v. 19, n. 3, p. 432-437, jul./set. 2011.

FREITAS, G. F.; OGUISSO, T.; RUIZ, M. D. C. S. Arqueologia do saber administrativo em enfermagem: Gênese e Incorporação nos discursos de Florence Nightingale e José Bueno Y González. In: OGUISSO, T. (org.). Enfermagem-História, cultura de cuidados e Métodos 1. ed. Rio de janeiro: Águia Dourada, 2016. p. 207-226.

LOPES, R. E.; NÓBREGA-THERRIEN, S. M. A nova ordem no Ceará e as consequências na formação e prática da enfermeira Cearense. In: CONGRESSO IBERO-AMERICANO EM INVESTIGAÇÃO QUALITATIVA, 7., 2018, Fortaleza. Atas... Fortaleza: Ludomedia, 2018. p.195-202.

LUCHESE, T. Modos de fazer história da educação: pensando a operação historiográfica em temas regionais. História da Educação, Porto Alegre, v. 18, n. 43, p. 145-161, maio./ago. 2014.

MELO, C. M. Divisão social do trabalho e enfermagem. 1 ed. São Paulo: Editora cortez, 1986.

NÓBREGA-THERRIEN, S. M; ALMEIDA, M. I. Enfermeira, profissão, saberes e prática: Potencialidades, limites e possibilidades. 1. ed. Fortaleza, Ceará: Ed. UECE, 2007.

LOPES, R. E.; NÓBREGA-THERRIEN, S. M. A nova ordem no ceará e as consequências na formação e a prática da enfermeira cearense. In: CONGRESSO IBERO-AMERICANO EM INVESTIGAÇÃO QUALITATIVA, 7., 2018, Fortaleza. Atas... Aveiro: Ludomedia, 2018. p. 195-202.

PARSONS, T. Ensayos de teoria sociológica. 1. ed. Buenos Aires: Paidos, 1967.

PESTANA, B. R.; PESSOA, S. B. Leishmaniose tegumentar autóctone no município de São Paulo. Annaes Paulistas de Medicina e Cirurgia, São Paulo, v. 40, n. 1, p. 71-72, 1940.

SANTOS, CAF. A enfermagem como profissão. 1. ed. São Paulo: Ed. Universidade de São Paulo, 1973.

SANTOS, R. M. et al. Circunstâncias de oficialização do curso de auxiliar de enfermagem no Brasil: estudando as entrelinhas da Lei 775/49. Revista Latino Americana de Enfermagem, São Paulo, v. 10, n. 4, p. 552-560, jul./ago. 2002.

SILVA, A. L.; PADILHA, M. I. C. S; BORENSTEIN, M. S. Imagem e identidade profissional na construção do conhecimento em enfermagem. Rev. Latino-Am. Enfermagem, São Paulo, v. 10, n. 4, p. 586-595, 2002.

SILVA, G. B. A enfermagem profissional: uma análise crítica. 1. ed. São Paulo: Cortez, 1986.

Recebido em: 28 de fevereiro de 2019.

Aceito em: 11 de maio de 2019. 